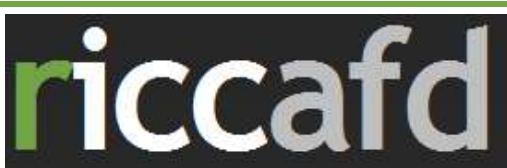

Revista Iberoamericana de Ciencias de la Actividad Física y el Deporte

\title{
IMPACTO DEL SUMINISTRO DE MONOHIDRATO DE CREATINA EN DEPORTISTAS DE CANOTAJE THE IMPACT OF THE SUPPLY OF CREATINE MONOHYDRATE IN CANOEING ATHLETES
}

\author{
Almonacid Fierro, M.A. ${ }^{1}$ y Urzua Alul, L.A. ${ }^{2}$ \\ 1 Magister en gerencia pública, pos título en entrenamiento deportivo, docente Universidad Autónoma de \\ Chile - Talca. malmonacid@ind.cl \\ 2 Dr. En Ciencias del Ejercicio, Magister en Ciencias de la Actividad Física, docente Universidad Autónoma \\ de Chile - Talca. aurzua@utalca.cl
}

Código UNESCO: 5802.99

Clasificación Consejo de Europa: 2.Bioquímica del deporte.

Recibido el 16 de noviembre de 2012

Aceptado el 14 de enero de 2013

PALABRAS
CLAVE:
Monohidrato
de Creatina,
Fases de
carga
y mantención,
Creatinkinasa

capacidad aeróbica para deportes naúticos de resistencia.

\section{RESUMEN}

El propósito de este trabajo fue determinar el impacto del suministro de monohidrato de creatina en deportistas de canotaje del programa CER del Instituto Nacional de Deportes de Chile en Talca. Fueron estudiados los sujetos que constituyen la selección regional de deportistas del programa. El procedimiento consistió en suministrar Monohidrato de Creatina en dos ciclos para fases de carga, mantención y sin aporte durante dos mesosiclos del período básico del Macrociclo 2012. Para evaluar el rendimiento deportivo se aplicaron test de Fuerza Máxima y Test de rendimiento específico en agua. Para determinar el nivel de esfuerzo se midió Creatinkinasa en sangre. Se evaluó además el porcentaje de masa grasa y encuesta alimentaria.

Los resultados del estudio muestran mejorías significativas en niveles de fuerza máxima coincidentes con lo expresado en la literatura, aportando conocimiento nuevo respecto de los beneficios en pruebas anaeróbicas y de

\section{ABSTRACT}

KEY WORDS:

Creatine

Monohydrate, stages of loading and maintenance Creatinkinasa

The purpose of this study was to determine the impact of the supply of creatine monohydrate in canoeing athletes belonging to the CER program of the National Sports Institute of Chile in the city of Talca. We studied the people who constitute the regional selection program for athletes. The procedure was to provide Creatine Monohydrate in two cycles during loading, maintenance and brazing for two basic mesosiclos in basic period of Macrocycle 2012. To evaluate athletic performance tests were applied maximum force and specific performance test in water. To determine the level of effort was measured in blood creatine kinase. It also assessed the percentage of fat mass and Food Survey.

Study results show significant improvements in maximal strength levels consistent with what is stated in the literature, providing new knowledge on the benefits in anaerobic tests and aerobic capacity to endurance watersports. 


\section{INTRODUCCIÓN}

Esta investigación se sustenta en los objetivos descritos en el programa C.E.R. "Apoyar técnicametodológica y científicamente a los deportistas en su proceso de entrenamiento de Alto Rendimiento" (IND, 2012 p.2.) y en la escasa investigación sobre suplementación mediante ayudas ergogénicas a deportistas practicantes de canotaje en Chile.

A lo largo de la historia se ha ido incrementando el nivel de exigencia de los deportistas: las marcas mejoran en un corto espacio de tiempo y tienen que seguir mejorando. Los entrenamientos se individualizan según las características del deportista, con lo que su técnica se optimiza. La atención y el cuidado de todos los detalles puede representar una diferencia fundamental para conseguir el objetivo prioritario: mejorar la marca, ampliar la ventaja con el contrincante y en definitiva ganar. Las ayudas ergogénicas (del griego ergón que significa trabajo) teóricamente permiten al individuo realizar más trabajo físico del que sería posible sin ellas (Wootton, cit. en Garnés y Mas, 2005).

El principal objetivo de la suplementación oral con Monohidrato de Creatina es aumentar la concentración de Creatina en el cuerpo y de este modo incidir en la mejora del rendimiento deportivo. Para aportar a la solución del problema, se pretende realizar el estudio sobre el efecto del suministro de Monohidrato de Creatina en deportistas pertenecientes al programa C.E.R. de canotaje en la ciudad de Talca, el cual considera a deportistas de edades comprendidas entre 15 - 18 años. Se debe destacar que este programa (C.E.R), reúne a los mejores exponentes de cada disciplina de las respectivas regiones, en función de criterios técnicos establecidos por cada disciplina deportiva (IND 2012, p. 21). En este contexto surge la problemática ¿cuál es el impacto que tiene el suministro de monohidrato de creatina en deportistas pertenecientes al programa C.E.R. de canotaje, en la ciudad de Talca, región del Maule?. El objetivo general de la investigación es "Conocer el efecto del suministro de Monohidrato de Creatina en deportistas pertenecientes al programa C.E.R. de canotaje, con edades comprometidas entre 14 - 18 años, durante el desarrollo de dos mesosiclos del periodo específico correspondientes al macrociclo 2012 en la ciudad de Talca, Región del Maule"

El monohidrato de creatina (en adelante MC) es una ayuda ergogénica utilizada por deportistas para aumentar el rendimiento deportivo, son consideradas como una fuente de alimentación primordial en los deportes que impliquen alto gasto de energía y así ser suplidas por estas sustancias (Barbany cit. en Arasa, 2005), describe las ayudas ergogénicas como cualquier medida, de cualquier índole, dirigida a mantener en lo posible el nivel de prestación deportiva, que minimiza las manifestaciones objetivas $y$ subjetivas de la fatiga y que no

Rev. Ib. CC. Act.Fis. Dep. 
pone en peligro la salud del deportista.

Según González, Sánchez. \& Mataix (2006) indica que, se han llegado a identificar al menos cinco categorías de las citadas ayudas ergogénicas:

- Ayudas mecánicas tales como zapatillas, mallas 0 cinturones.

- Ayudas psicológicas como la hipnosis o la psicoterapia.

- Ayudas fisiológicas como el dopaje sanguíneo.

- Ayudas farmacológicas, como la cafeína o diversos antioxidantes.

- Ayudas nutricionales como sobrecarga de carbohidratos o creatina.

La creatina es una sustancia que nuestro organismo produce en pequeñas cantidades de manera habitual y es semejante en su composición a un aminoácido. La podemos encontrar en distintos alimentos naturales como en la carne y en el pescado, además es creada por nuestro organismo en el hígado, páncreas y el riñón a través de aminoácidos. El hígado es el responsable de combinar los elementos de arginina, glycina y metionina y formular la creatina. Es almacenada y utilizada para suplir de energía a nuestros músculos. A parte de encontrarse en nuestro cuerpo, podemos suplir la creatina a través de suplementos alimenticios fáciles de adquirir.

Según Bean, (2005) el MC permite el aumento de la duración de ejercicios de alta intensidad de poca duración ya que actúa como freno

Rev. lb. Cᄃ. Act.Fis. Dep. de la aparición de ácido láctico, al aumentar la duración del metabolismo anaeróbico aláctico. Al tomar creatina aumentamos el número y la cantidad de proteínas musculares, con lo que la masa muscular se puede ver aumentada si realizamos ejercicios específicos para ello.

El MC es solo una molécula de creatina con una molécula de agua que le confiere estabilidad. (Bean, A. 2005). La administración de creatina unida al entrenamiento de fuerza aumenta más la masa corporal, la masa libre de grasa y la fuerza que el entrenamiento de fuerza aislado, tanto en las mujeres como en los hombres. (González, et. al 2006)

La creatina es una sustancia que nuestro organismo produce en pequeñas cantidades de manera habitual y es semejante en su composición a un aminoácido. La podemos encontrar en distintos alimentos naturales como en la carne y en el pescado, además es creada por nuestro organismo en el hígado, páncreas y el riñón a través de aminoácidos. El hígado es el responsable de combinar los elementos de arginina, glycina $y$ metionina y formular la creatina, la cual es almacenada y utilizada para suplir de energía a nuestros músculos. Aparte de encontrarse en nuestro cuerpo, podemos suplir la creatina a través de suplementos alimenticios fáciles de adquirir.

El $95 \%$ de la $\mathrm{Cr}$ de un ser humano se encuentra en sus músculos, ya que es un combustible esencial para el funcionamiento muscular. Los 2-4 g/día que necesitamos de $\mathrm{Cr}$ para sobrevivir son obtenidos de 
la dieta (1-2 g/día) y la síntesis endógena de $\mathrm{Cr}$ (1-2 g/día). (López, Fernández 2006).

La creatina es un suplemento extremadamente popular entre deportistas para mejorar su rendimiento, toda vez que se trata de una sustancia presente en la carne y el pescado y fabricada en el hígado. Las células musculares utilizan la creatina para generar energía. (Richardson 2001 ), por otro lado, puesto que las células musculares no poseen la capacidad de sintetizar $\mathrm{Cr}$, ésta debe ser transportada a su interior desde el torrente sanguíneo, puesto que la concentración de $\mathrm{Cr}$ es mayor en el interior de las células musculares que en el plasma.

La administración de creatina unida al entrenamiento de fuerza aumenta más la masa corporal, la masa libre de grasa y la fuerza que el entrenamiento de fuerza aislado, tanto en las mujeres como en los hombres. (González, et al 2006)

La suplementación con creatina parece tener ciertos beneficios ergogénicos, sobre todo en el aumento del contenido en creatina del músculo esquelético, y la mejora del rendimiento en tandas de ejercicio máximo de corta duración, entre 30 y 150 segundos. Las evidencias son menos claras en lo que concierne a su capacidad para aumentar la masa y fuerza musculares. (Wilmore, Costill, 2007)

En relación a la especialidad deportiva de los sujetos investigados podemos decir que el canotaje o canoismo, también conocido como piragüismo, es uno de los deportes más antiguos que existe, puesto que en los antiguos orígenes el hombre ha tenido que dominar los distintos obstáculos, uno de ellos es el agua. Para ello las antiguas civilizaciones construyeron pequeñas embarcaciones utilizando sus árboles que les sirviese para ser operadas en agua, con características muy peculiares, pero de una gran maniobrabilidad, seguras y eficaces. Es un deporte practicado sobre una embarcación llamada kayak o canoa, está construida de fibra de vidrio para embarcaciones de competición y otras construidas de plástico en el caso de actividades recreativas.

En relación al contexto de la investigación esta se desarrolla al interior del programa de Centros de Entrenamiento Regionales (CER) implementados el año 1997 en cada una de las regiones del Chile, con el nombre de "Programa Nacional de los Centros de Iniciación y Especialización Deportiva (CIED)". Esta iniciativa consistió en crear el espacio necesario para formar, desarrollar y potenciar a deportistas con talento deportivo a nivel regional, con miras al deporte de alto rendimiento, en el marco de La Ley del Deporte $N^{\circ} 19.712$ que en su artículo 8을 define al deporte de alto rendimiento y proyección internacional como aquel que implica una práctica sistemática de alta exigencia en la respectiva especialidad deportiva. En su articulado considera como deportistas de alto rendimiento a "aquellos que cumplan con las exigencias técnicas que establece el Instituto Nacional de Deportes, el Comité Olímpico de Chile y las

Rev. Ib. CE. Act.Fis. Dep. 
Federaciones

Deportivas

Nacionales, afiliadas a este último" (IND, 2012)

\section{DISEÑO Y METODOLOGIA}

El diseño de investigación es experimental y el tipo de muestreo es no probabilístico, en el marco de un estudio cuantitativo, tomando como muestra a jóvenes que están dentro de rangos de edades del programa CER financiado por el gobierno, que serán determinantes en la entrega de resultados.

El estudio considera a dos grupos aleatorios, un grupo seria el grupo experimental y el otro, el de control. Los sujetos se distribuyen de forma aleatoria en cada uno de ellos.

Esta premeditación del valor de la variable dependiente ayuda a una mejor comprobación del efecto del tratamiento aplicado, al conocerse el valor de la variable dependiente antes y después de la intervención experimental. Además, puede conocerse la cantidad exacta de la variación de una prueba y otra, en los dos grupos de tratamiento (Latorre, Del Rincón, Arnal, 1996)

\section{Población}

Dado que la cantidad de deportistas pertenecientes al programa CER de Canotaje del Instituto Nacional de Deportes (IND) es muy reducida, se tomó la decisión de incorporar al $100 \%$ de los sujetos pertenecientes al programa $(n=6)$, los cuales forman parte de un grupo de jóvenes entre 14 y 18 años, que residen en sectores con vulnerabilidad tanto social como deportiva, que son estudiantes de colegios y liceos municipales. Dentro de los 6 deportistas contamos con 5 hombres y 1 mujer, donde el $66,7 \%$ corresponde al grupo experimental con MC.

De los 6 deportistas que integraron inicialmente el proyecto, uno de ellos, sufrió un cuadro respiratorio que lo inhabilitó para desarrollar con normalidad el proceso, afectando su peso corporal (reducción de peso por deshidratación), lo que obligó a excluirlo de la presente investigación, con la finalidad de contar con información objetiva sobre la marcha de la preparación.

Por lo anterior, el estudio se realizó sobre 5 deportistas, de los cuales 3 de ellos (60\%) constituyeron el grupo experimental y 2 de ellos (40\%) el grupo control.

Los criterios considerados para determinar el grupo de estudio, dependen principalmente de formar un grupo homogéneo con la integración de dos géneros, masculino y femenino, dentro de los cuales consideramos las edades comprometidas, rendimientos a nivel deportivo, características físicas, corporalmente parecidos y que tuvieran proyección en el ámbito deportivo, para estudios posteriores con ellos en su evolución hacia el alto rendimiento.

\section{Entrenamiento}

En conjunto con el entrenador responsable se estructuró un plan de entrenamiento que consta de dos Mesociclos correspondientes al período básico del segundo Macrociclo 2012, compuesto de cuatro Microciclos por cada Mesociclo (Dietrich, Klaus y Klaus, 2001).

Rev. Ib. CC. Act.Fis. Dep. 
Mesociclo 1 y Mesociclo 2

Corresponden a los meses de Mayo y Junio, donde se trabajó cuatro Microciclos por cada mes, cada uno de ellos con trabajo de seis días a la semana donde el día lunes se da como día de descanso.

Cada día de entrenamiento se ejecuta una doble jornada donde se trabaja primeramente en horas aguas, tanto un trabajo de potencia, resistencia 0 velocidad, para posteriormente ejecutar un trabajo físico en gimnasio. Además de estos trabajos cada semana nuestros deportistas asistieron a una sesión de apoyo psicológico, entregado por personal correspondiente al IND Talca, para mejorar y fortalecer la concentración, ansias, desgaste psicológico, nervios antes, durante y después de una competencia.

Cada sesión de entrenamiento contaba con el $100 \%$ de los deportistas, ya sea en trabajo de agua como en trabajo físico, para ello es importante estructurar evaluaciones correspondientes en cada etapa del entrenamiento, de este modo, en conjunto con el entrenador del grupo de deportistas se han construido evaluaciones que muestran el rendimiento de cada uno de los evaluados tanto antes, como durante y después de la ingesta del monohidrato de creatina. En los siguientes puntos de la investigación se explicarán cada uno de los test y evaluaciones aplicadas en el plan de entrenamiento correspondiente al trabajo de los deportistas (Richardson, 2001; Vasconcelos, 2005).
Sesión de entrenamiento Corresponde a la sesión de entrenamiento que forma parte de microciclos y que a su vez forman parte de dos mesociclos correspondientes al Macrociclo del año 2012. A continuación, se detalla las características de la sesión.

\section{Características Generales}

Se trata de 48 sesiones de entrenamiento supervisadas, distribuidas en forma semanal en microciclos. Se realiza la actividad física con una frecuencia de dos veces por día, en seis días correspondientes, durante dos meses. Esta actividad, además se coordinó con otras actividades del programa, como entrevistas psicológicas, charlas nutricionales, exámenes.

Cada sesión de entrenamiento contaba con el $100 \%$ de la asistencia de cada deportista que se encuentra en el programa.

El proceso de entrenamiento fue dirigido por el profesor de Educación Física, Entrenador del equipo quien en el marco del segundo Macrociclo correspondiente al Plan Anual 2012, llevó a cabo la preparación de dos mesosiclos del período básico según el detalle que se muestra a continuación:

Rev. Ib. CC. Act.Fis. Dep. 


\begin{tabular}{|c|c|c|c|c|c|c|c|c|}
\hline \multicolumn{9}{|c|}{ PLAN DE ENTRENAMIENTO } \\
\hline & \multicolumn{4}{|c|}{ Mesociclo 1 (Mayo) } & \multicolumn{4}{|c|}{ Mesociclo 2 (Junio) } \\
\hline & Microciclo 1 & Microciclo 2 & Microciclo 3 & Microciclo 4 & Microcicclo 1 & Microcicclo 2 & Microcicclo 3 & Microcicclo 4 \\
\hline Lunes & DESCANSO & DESCANSO & DESCANSO & DESCANSO & DESCANSO & DESCANSO & DESCANSO & DESCANSO \\
\hline Martes & & & & & & TROTE & & \\
\hline Miércoles & $\begin{array}{c}\text { RIO (freno) } \\
\text { GIMNASIO } \\
\text { (fuerza) }\end{array}$ & $\begin{array}{l}\text { RIO (freno) } \\
\text { GIMNASIO } \\
\text { (fuerza) }\end{array}$ & $\begin{array}{l}\text { RIO (freno) } \\
\text { GIMNASIO } \\
\text { (fuerza) }\end{array}$ & $\begin{array}{c}100 \mathrm{MT} \\
\text { VELOCIDAD } \\
\text { 8km SUAVE } \\
\text { GIMNASIO } \\
\end{array}$ & $\begin{array}{l}\text { RIO (freno) } \\
\text { GIMNASIO } \\
\text { (fuerza) }\end{array}$ & $\begin{array}{c}\text { RIO (freno) } \\
\text { GIMNASIO } \\
\text { (fuerza) }\end{array}$ & $\begin{array}{c}\text { RIO (freno) } \\
\text { GIMNASIO } \\
\text { (fuerza) }\end{array}$ & $\begin{array}{c}\text { RIO (freno) } \\
\text { GIMNASIO } \\
\text { (fuerza) }\end{array}$ \\
\hline Jueves & \begin{tabular}{|c|} 
RIO \\
(controlados) \\
GIMNASIO \\
(resistencia) \\
\end{tabular} & $\begin{array}{c}\text { RIO } \\
\text { (controlados) } \\
\text { GIMNASIO } \\
\text { (resistencia) } \\
\end{array}$ & $\begin{array}{c}\text { RIO } \\
\text { (controlados) } \\
\text { GIMNASIO } \\
\text { (resistencia) } \\
\end{array}$ & $\begin{array}{c}\text { RIO } \\
\text { (controlados) } \\
\text { GIMNASIO } \\
\text { (resistencia) } \\
\end{array}$ & $\begin{array}{c}\text { RIO } \\
\text { (controlados) } \\
\text { GIMNASIO } \\
\text { (resistencia) } \\
\end{array}$ & $\begin{array}{c}\text { RIO } \\
\text { (controlados) } \\
\text { GIMNASIO } \\
\text { (resistencia) } \\
\end{array}$ & \begin{tabular}{|c|}
$\mathrm{RIO}$ \\
(controlados) \\
GIMNASIO \\
(resistencia) \\
\end{tabular} & $\begin{array}{c}\text { RIO } \\
\text { (controlados) } \\
\text { GIMNASIO } \\
\text { (resistencia) } \\
\end{array}$ \\
\hline Viernes & $\begin{array}{c}\text { RIO (freno) } \\
\text { GIMNASIO } \\
\text { (fuerza) }\end{array}$ & $\begin{array}{l}\text { RIO (freno) } \\
\text { GIMNASIO } \\
\text { (fuerza) }\end{array}$ & $\begin{array}{l}\text { RIO (freno) } \\
\text { GIMNASIO } \\
\text { (fuerza) }\end{array}$ & $\begin{array}{l}\text { RIO (freno) } \\
\text { GIMNASIO } \\
\text { (fuerza) }\end{array}$ & $\begin{array}{l}\text { RIO (freno) } \\
\text { GIMNASIO } \\
\text { (fuerza) }\end{array}$ & $\begin{array}{l}\text { RIO (freno) } \\
\text { GIMNASIO } \\
\text { (fuerza) }\end{array}$ & $\begin{array}{c}\text { RIO (freno) } \\
\text { GIMNASIO } \\
\text { (fuerza) }\end{array}$ & $\begin{array}{c}\text { RIO (freno) } \\
\text { GIMNASIO } \\
\text { (fuerza) }\end{array}$ \\
\hline Sábado & \begin{tabular}{|c|} 
RIO \\
(controlados) \\
GIMNASIO \\
(resistencia) \\
\end{tabular} & $\begin{array}{c}\text { RIO } \\
\text { (controlados) } \\
\text { GIMNASIO } \\
\text { (resistencia) } \\
\end{array}$ & $\begin{array}{c}\text { RIO } \\
\text { (controlados) } \\
\text { GIMNASIO } \\
\text { (resistencia) }\end{array}$ & $\begin{array}{c}\text { RIO } \\
\text { (controlados) } \\
\text { GIMNASIO } \\
\text { (resistencia) } \\
\end{array}$ & $\begin{array}{c}\text { RIO } \\
\text { (controlados) } \\
\text { GIMNASIO } \\
\text { (resistencia) } \\
\end{array}$ & $\begin{array}{c}\text { RIO } \\
\text { (controlados) } \\
\text { GIMNASIO } \\
\text { (resistencia) } \\
\end{array}$ & \begin{tabular}{|c|} 
RIO \\
(controlados) \\
GIMNASIO \\
(resistencia) \\
\end{tabular} & $\begin{array}{c}\text { RIO } \\
\text { (controlados) } \\
\text { GIMNASIO } \\
\text { (resistencia) }\end{array}$ \\
\hline Domingo & $\begin{array}{c}\text { FRENO } \\
\text { ARRASTRE } \\
\text { TROTE } \\
\text { INDIVIDUAL }\end{array}$ & $\begin{array}{c}\text { FRENO } \\
\text { ARRASTRE } \\
\text { TROTE } \\
\text { INDIVIDUAL }\end{array}$ & $\begin{array}{c}\text { FRENO } \\
\text { ARRASTRE } \\
\text { TROTE } \\
\text { INDIVIDUAL }\end{array}$ & $\begin{array}{c}\text { FRENO } \\
\text { ARRASTRE } \\
\text { TROTE } \\
\text { INDIVIDUAL }\end{array}$ & $\begin{array}{c}\text { FRENO } \\
\text { ARRASTRE } \\
\text { TROTE } \\
\text { INDIVIDUAL }\end{array}$ & $\begin{array}{c}\text { FRENO } \\
\text { ARRASTRE } \\
\text { TROTE } \\
\text { INDIVIDUAL }\end{array}$ & \begin{tabular}{|c|} 
FRENO \\
ARRASTRE \\
TROTE \\
INDIVIDUAL
\end{tabular} & \begin{tabular}{|c|} 
FRENO \\
ARRASTRE \\
TROTE \\
INDIVIDUAL
\end{tabular} \\
\hline
\end{tabular}

Tabla 1. Distribución de los entrenamientos durante los mesociclos.

\section{Variables/Tópicos de estudio}

\section{Nivel de suministro de monohidrato de creatina}

Es importante conocer cuál es el nivel de suministro que consumirá cada deportista en sus diferentes periodos de entrenamiento. Para ello es necesario averiguar, identificar y recolectar la mayor información de la dosificación adecuada para que la experimentación sea efectiva.

La literatura señala que el protocolo de carga de de creatina más corriente empleado en los estudios realizados durante la década de 1990 ha sido 4 dosis de $5-7 \mathrm{~g}$ al día durante un período de 5 días, es decir, 20 - 25 g diarios (Bean, 2005; Santos et al. 2003)

Roberts y O'Brien (2003) expresan que, quienes proponen los

Rev. Ib. CE. Act.Fis. Dep. suplementos de creatina recomiendan empezar con una dosis de carga relativamente elevada, de una cucharada de café $(5 \mathrm{~g})$ cuatro o cinco veces al día durante los primeros $5-7$ días, y

luego reducir hasta una cucharada de café dos veces al día cada dos días, o no más de cinco días a la semana. La dosis optima de mantenimiento para conseguir los niveles de creatina musculares adecuados en los deportistas que entrenan intensamente se desconoce, pero $2 \mathrm{~g}$ diarios pueden ser suficiente, ya que cantidades mayores $(5 \mathrm{~g})$ pueden aumentar la concentración total de creatina extracelular y producir inhibición de su transporte al interior de la celular muscular (González et al. 2006).

Respecto de la dosificación planteada en nuestro estudio, para el primer ciclo en la fase de 
asimilación se inició con una cantidad de 1 grs. diarios por deportista durante una semana, a esta le siguieron 2 semanas de carga con 2 grs. diarios, luego se suspendió el suministro de MC por una semana.

El segundo ciclo comienza con una fase de carga durante dos semanas que considera 2 grs. diarios de $\mathrm{MC}$, a la cual le sigue una semana de mantención con 1 grs. diarios y finalmente una semana sin suplementación.

\begin{tabular}{lcc}
\hline FASE & $\begin{array}{c}\text { MC } \\
\text { (gramos) }\end{array}$ & FECHA \\
\hline $\begin{array}{l}\text { Fase } \\
\text { Introducción }\end{array}$ & 1 gramo & $30 / 04-06 / 05$ \\
$\begin{array}{l}\text { Fase de } \\
\text { Carga }\end{array}$ & 2 gramos & $07 / 05-20 / 05$ \\
$\begin{array}{l}\text { Fase sin } \\
\text { Suplemento }\end{array}$ & --- & $21 / 05-27 / 05$ \\
$\begin{array}{l}\text { Fase de } \\
\text { Carga }\end{array}$ & 2 gramos & $28 / 05-10 / 06$ \\
$\begin{array}{l}\text { Fase de } \\
\text { Mantención }\end{array}$ & 1 gramo & $11 / 06-17 / 06$ \\
$\begin{array}{l}\text { Fase sin } \\
\text { Suplemento }\end{array}$ & --- & $18 / 06-24 / 06$ \\
\hline
\end{tabular}

Tabla 2. Dosificación de monohidrato de creatina a lo largo de la fase experimental

\section{Resultados}

El análisis de los datos se efectuó mediante el programa de software denominado Statistical Package for the Social Sciences (SPSS).

Para el análisis de la primera hipótesis se utilizó la t-Student para verificar diferencias significativas entre pre-test y post-test que fueron realizados, dicho análisis se efectuó mediante el software estadístico SPSS versión 20, 2011 de IBM incorporated.

Rev. Ib. Cᄃ. Act.Fis. Dep.

\section{Examen de (Creatinkinasa) \\ sangre}

La CK, también conocida como fosfocreatina kinasa o CK, es una proteína del grupo conocido como enzimas. Estas enzimas son catalizadores químicos, 0 sea permite que ciertas reacciones bioquímicas, que naturalmente no ocurren, ocurran en nuestro organismo. La función normal de la CK en nuestras células es adicionar un grupo químico de fosfatos a la creatina, convirtiéndola en una la molécula de fosfocreatina de altaenergía. La fosfocreatina es quemada entonces como una fácil fuente de energía por nuestras células. Para la medición de los niveles de CK, se toma una muestra de sangre y se separa en partes que contienen células sanguíneas y partes sin ellas -0 serum sanguíneo. La cantidad de CK en el serum es medida en unidades (U) de enzima activa por litro (L) de serum. En un adulto sano, los niveles de CK en el serum varían por varios factores, tales como género, raza y actividad, pero el rango normal es de entre 22 y 198 U/L (unidades por litro) (González et al. 2006; López y Fernandez, 2006; Wilmore y Costill, 2007).

Altas cantidades de CK en el serum pueden indicar un daño muscular, debido a una enfermedad crónica o a una aguda lesión muscular. Es por esta razón, que si a usted le van a realizar un examen sanguíneo de CK para diagnosticar un potencial desorden muscular, debe limitar el ejercicio y solo desarrollar las actividades normales antes del examen.

Para el caso de las tomas de muestras en laboratorio se contó con al laboratorio, de Chillan 
ubicado en calle 5 de Abril para la primera evaluación y 3 evaluaciones realizadas en el laboratorio del Hospital Regional de Talca. Ambos laboratorios certificados para la realización de este tipo de muestras.
Se realizaron fichas para cada test por deportista con la finalidad de hacer una comparación entre el pre y post test., de modo de establecer variaciones respecto a sus niveles.

\begin{tabular}{lc}
\hline EVALUACIONES CREATINKINASA (CK) & FECHA \\
\hline Evaluación $\mathrm{N}^{\circ} 1$ & $02 / 05-2012$ \\
Evaluación $\mathrm{N}^{\circ} 2$ & $23 / 05-2012$ \\
Evaluación $\mathrm{N}^{\circ} 3$ & $07 / 06-2012$ \\
Evaluación $\mathrm{N}^{\circ} 4$ & $13 / 06-2012$ \\
\hline
\end{tabular}

Tabla 3. Evaluaciones de la Creatinkinasa a lo largo del proceso experimentaln

Figura 1. Comparación de Creatinkinasa en sangre en $\mathrm{U} / \mathrm{L}$, muestra la diferencias entre el grupo control sin $\mathrm{MC}$ y el grupo experimental, donde se expone: el $1^{\circ}$ examen sin $\mathrm{MC}$, el $2^{\circ}$ y $3^{\circ}$ examen con $\mathrm{MC}$ y el $4^{\circ}$ examen $\sin$ MC.

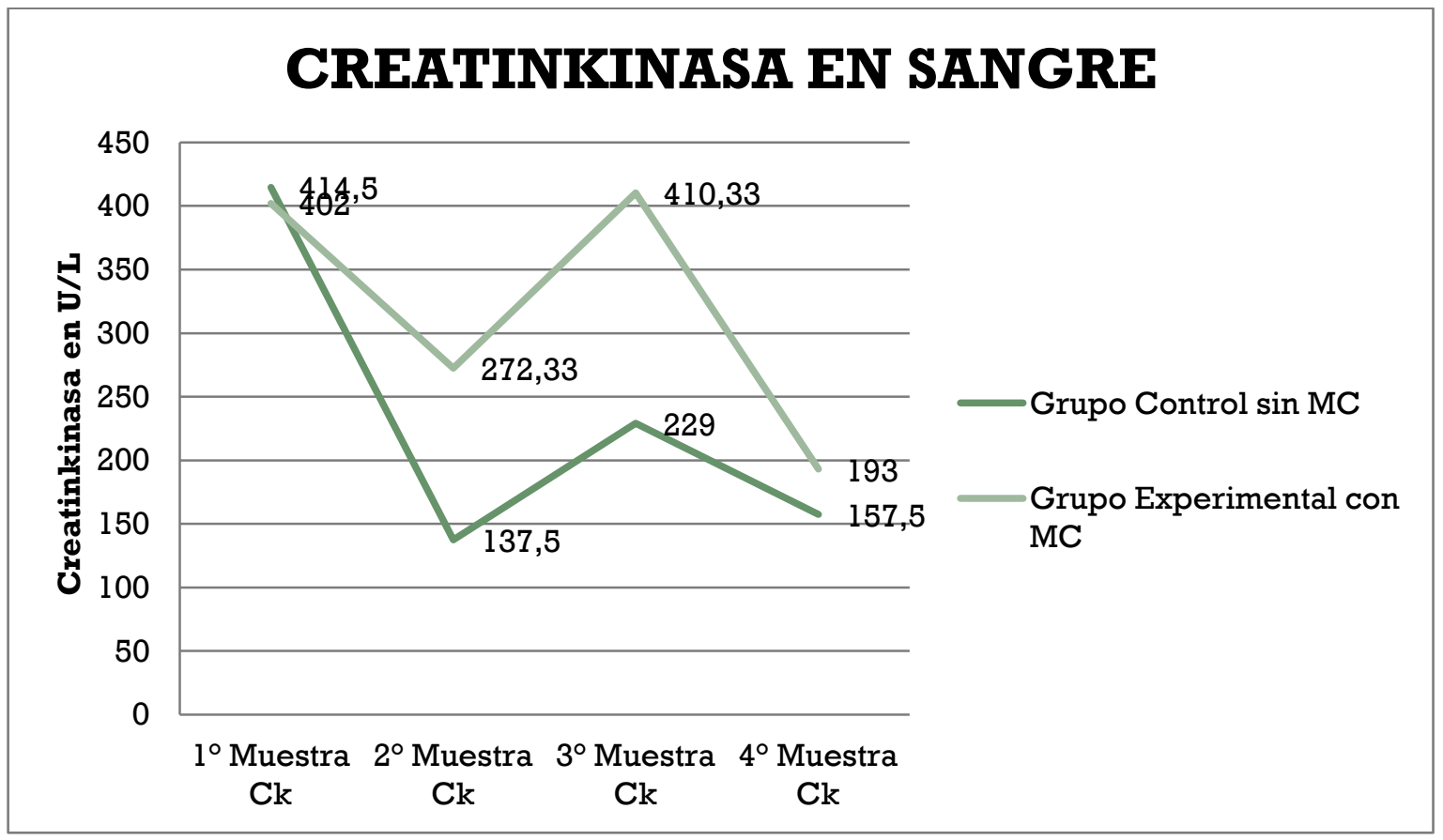

\section{Medición Antropométrica}

La medición antropométrica comprende mediciones de pliegues cutáneos, a partir de las cuales se desarrollan ecuaciones de regresión lineal para calcular la densidad

Rev. Ib. CL. Act.Fis. Dep. corporal (por fórmulas, y no por peso hidrostático).

\section{Composición Corporal}

La masa grasa está constituida principalmente por el tejido adiposo subcutáneo y perivisceral con una 
densidad energética aproximada de 9000 Calorías por kg. La masa magra es metabólicamente más activa, está constituida en un $40 \%$ por la musculatura esquelética y tiene una densidad energética de 1000 Calorías por kg.

En el adulto sano, la masa grasa tiene valores de 10 a $20 \%$ en el hombre y de 15 a $30 \%$ en la mujer. El resto es masa magra o libre de grasa.

\section{Antropometría:}

1) Peso, talla e IMC, es un indicador global del estado nutricional ya descrito.

2) Pliegues cutáneos a nivel bicipital, tricipital, subescapular y suprailíaco mediante un caliper.

3) Perímetro muscular braquial (PMB), usando el perímetro del brazo (PB) y el pliegue tricipital (PT) se calcula este indicador de la masa muscular $\mathrm{PMB}=\mathrm{PB}$ en $\mathrm{cm}-(\pi \mathrm{x}$ PT en $\mathrm{cm}$ )

4) Dinamometría, con un dinamómetro se mide la fuerza muscular del brazo.

5) Perímetro de cintura: con una cinta en el punto medio entre el reborde costal y la cresta ilíaca. Es un indicador de grasa intrabdominal. Los valores normales son menos de $88 \mathrm{~cm}$ en la mujer y $102 \mathrm{~cm}$ en el hombre

Las mediciones antropométricas se efectuaron en las instalaciones del Laboratorio de Fisiología de la Universidad Autónoma Sede Talca, a cargo de evaluadores certificados.

\section{Evaluación Ingesta nutricional}

El objetivo de la Evaluación Nutricional es determinar las calorías y nutrientes ingeridos en las distintas raciones alimentarias, permitiendo evaluar el modo de alimentación del grupo, pudiendo conocer también si los hábitos alimentarios y la ingesta de nutrientes son adecuados, con respecto al nivel de entrenamiento que tiene cada uno de los individuos.

\section{Test Físicos}

Los Test Físicos considerados en la investigación se escogieron con el propósito de que constituyeran primeramente una información relevante sobre el desarrollo del proceso de preparación y seguidamente, pudieran dar cuenta del impacto sobre el rendimiento deportivo de los canoistas y kayakistas que podría tener el suministro de Monohidrato de Creatina.

\section{Test $1 k$ y $2 k$ en la embarcación}

Son test que tienen como objetivo valorar la capacidad aeróbicaanaeróbica y capacidad aeróbica de un deportista en trabajo. Su desarrollo consiste en recorrer las distancias determinadas $(1.000 \mathrm{y}$ $2.000 \mathrm{mts}$.) sobre la embarcación en el menor tiempo posible, anotando el tiempo cada $250 \mathrm{mts}$. Hasta que llegue a su finalización.

Estos test se efectuaron en las dependencias del lugar de entrenamiento (Rio Claro, Talca), tiempos del recorrido cada $250 \mathrm{mts}$. hasta llegar a completar el circuito, se debió anotar en una hoja de registro el tiempo que hizo cada deportista pasando por los puntos demarcados, hasta llegar a completar las respectivas distancias.

Rev. Ib. CE. Act.Fis. Dep. 
Figura 2. Comparación del resultado de test de Resistencia sobre 1 kilómetro, en segundos, en el que se muestran las diferencias entre el grupo control sin MC y grupo experimental donde indica la $1^{\circ}$ medición sin $\mathrm{MC}$, la $2^{\circ}$ medición con MC y la $3^{\circ}$ medición sin MC.

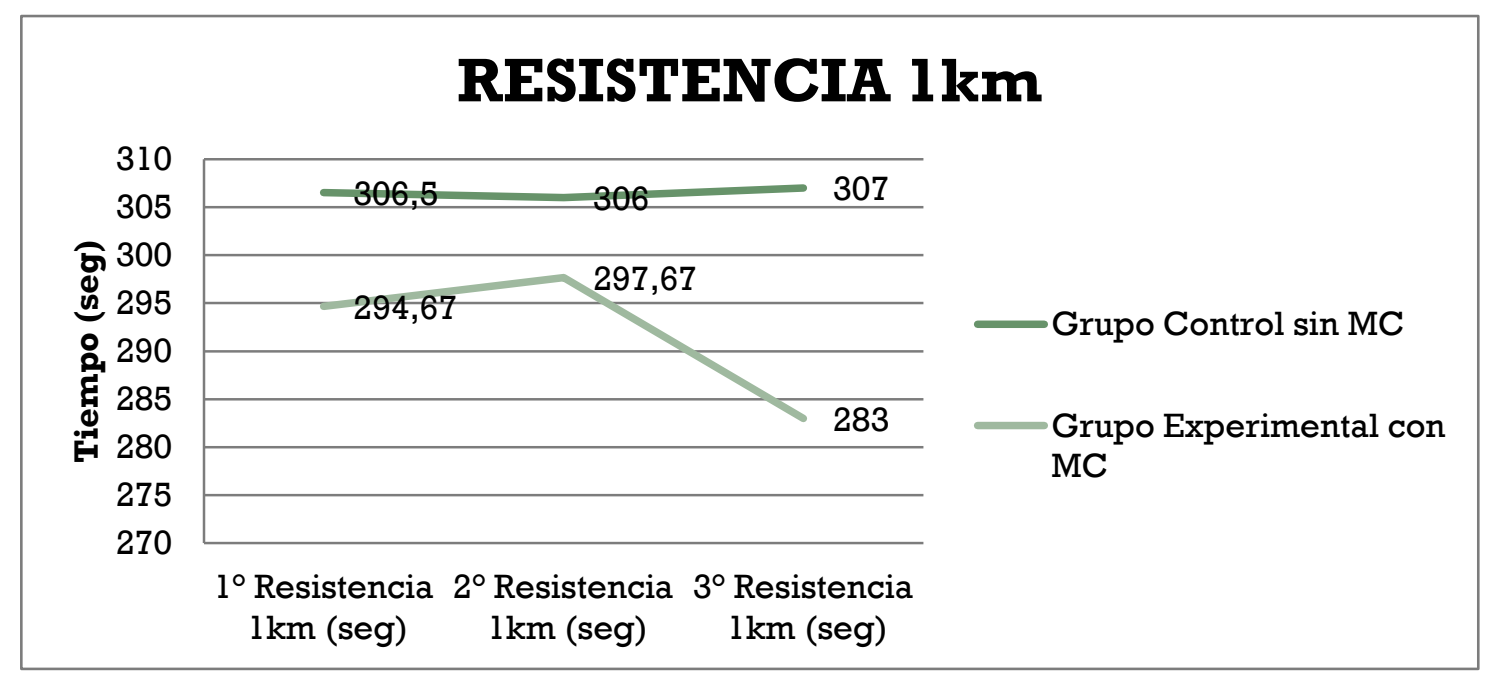

Figura 3. Comparación del resultado del test de resistencia sobre 2 kilómetros, en segundos, mostrando las diferencias entre el grupo control sin $\mathrm{MC}$ y el grupo experimental donde indica la $1^{\circ}$ medición sin $\mathrm{MC}$, la $2^{\circ}$ medición con $\mathrm{MC}$ y la $3^{\circ}$ medición sin MC.

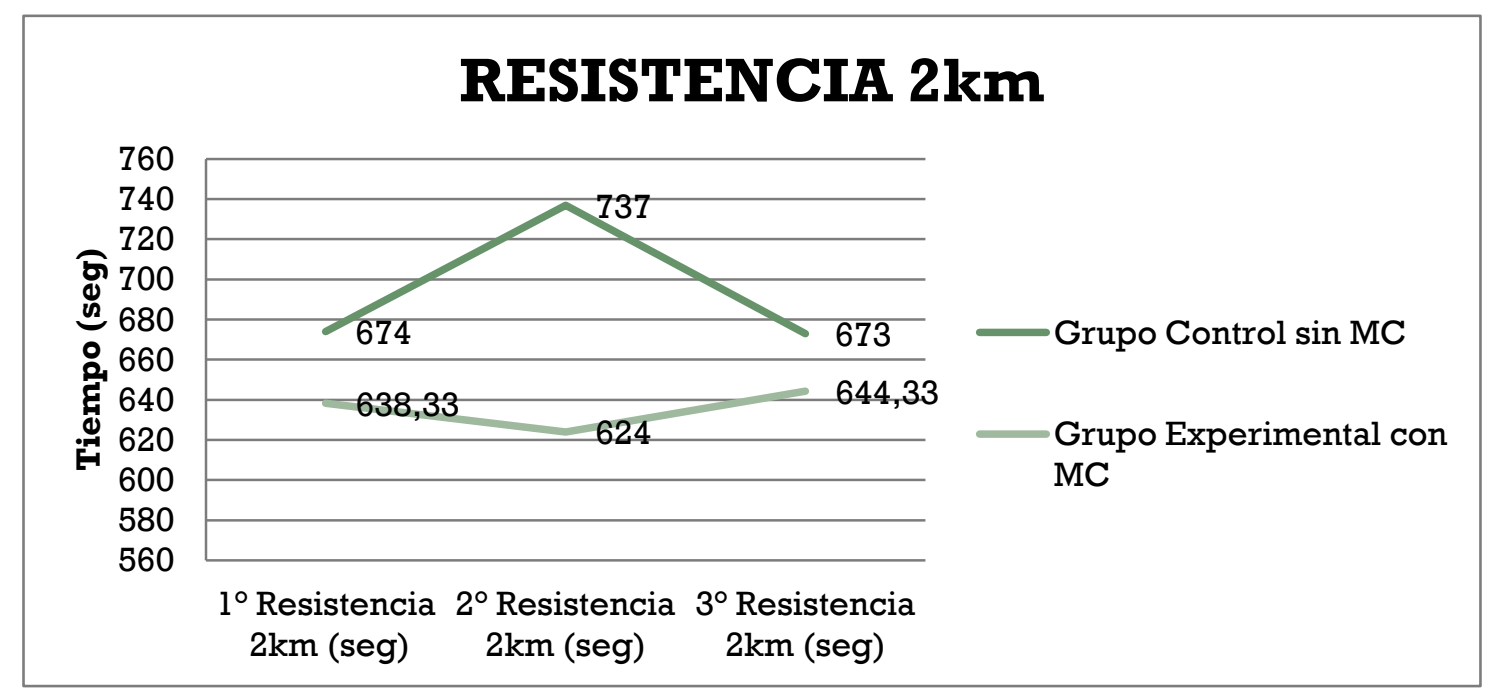

Test $500 \mathrm{mts}$. y $200 \mathrm{mts}$. en la embarcación

El test de $500 \mathrm{mts}$. es un test que tiene como objetivo determinar la capacidad anaeróbica láctica del deportista. Su desarrollo consiste en

Rev. Ib. CL. Act.Fis. Dep. recorrer la distancia estipulada sobre la embarcación en el menor tiempo posible (mayor velocidad). El test de $200 \mathrm{mts}$ es un test que tiene como objetivo determinar la potencia anaeróbica láctica del deportista. Su desarrollo consiste es recorrer la distancia estipulada 
sobre la embarcación en el menor tiempo posible (mayor velocidad). Su ejecución fue en las dependencias de entrenamiento (Rio Claro, Talca), donde desde el punto de partida se anotó previamente la frecuencia cardíaca de inicio, luego iniciaron el test a la mayor velocidad posible para anotar su tiempo y anotar su frecuencia cardiaca final. Después de cada minuto se volvió a tomar la frecuencia cardiaca, hasta llegar a un nivel óptimo. Los datos de tiempo y frecuencia cardiaca se anotaron en una hoja de registro estipulada para cada prueba

Figura 4. Comparación del resultado del test en agua sobre 500 metros en segundos, muestra las diferencias entre el grupo control sin MC y grupo experimental donde indica la $1^{\circ}$ medición sin MC, la $2^{\circ}$ medición con MC y la $3^{\circ}$ medición sin MC.

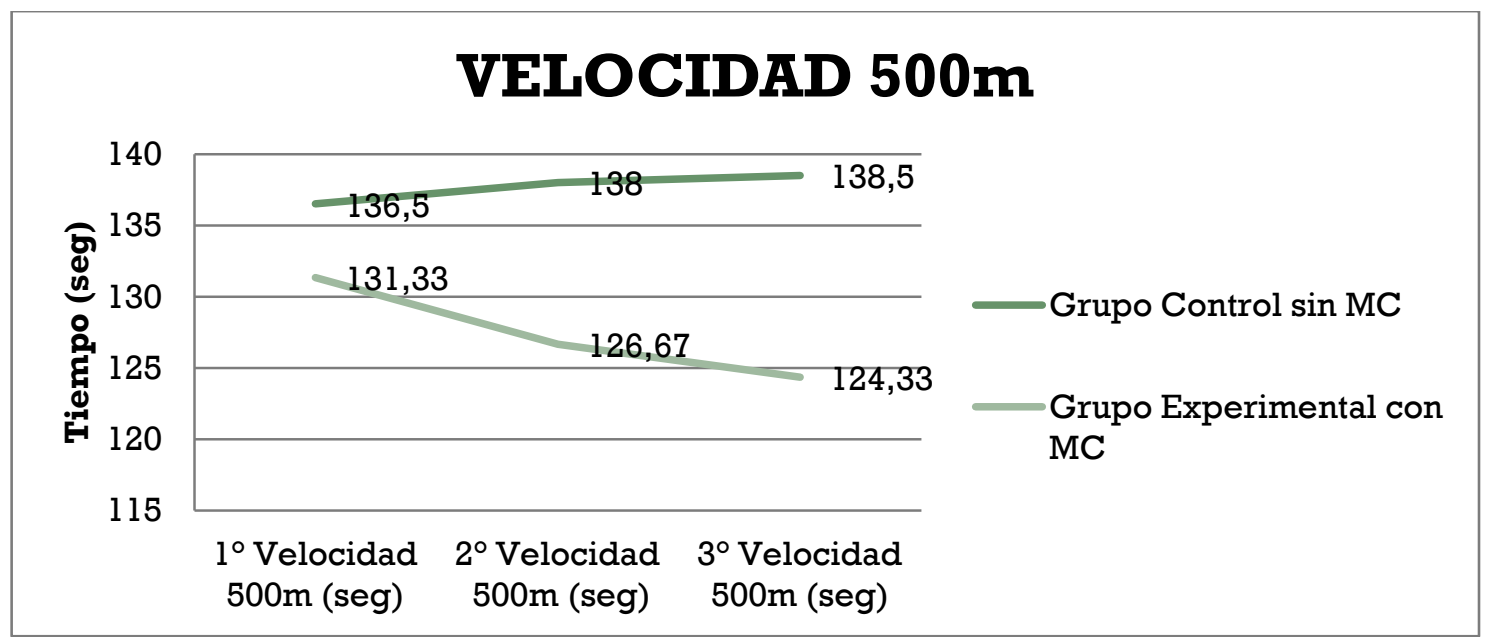

Figura 5. Comparación del resultado del test en agua sobre 200 metros en segundos, muestra las diferencias entre el grupo control sin MC y grupo experimental donde indica la $1^{\circ}$ medición sin MC, la $2^{\circ}$ medición con MC y la $3^{\circ}$ medición $\sin \mathrm{MC}$

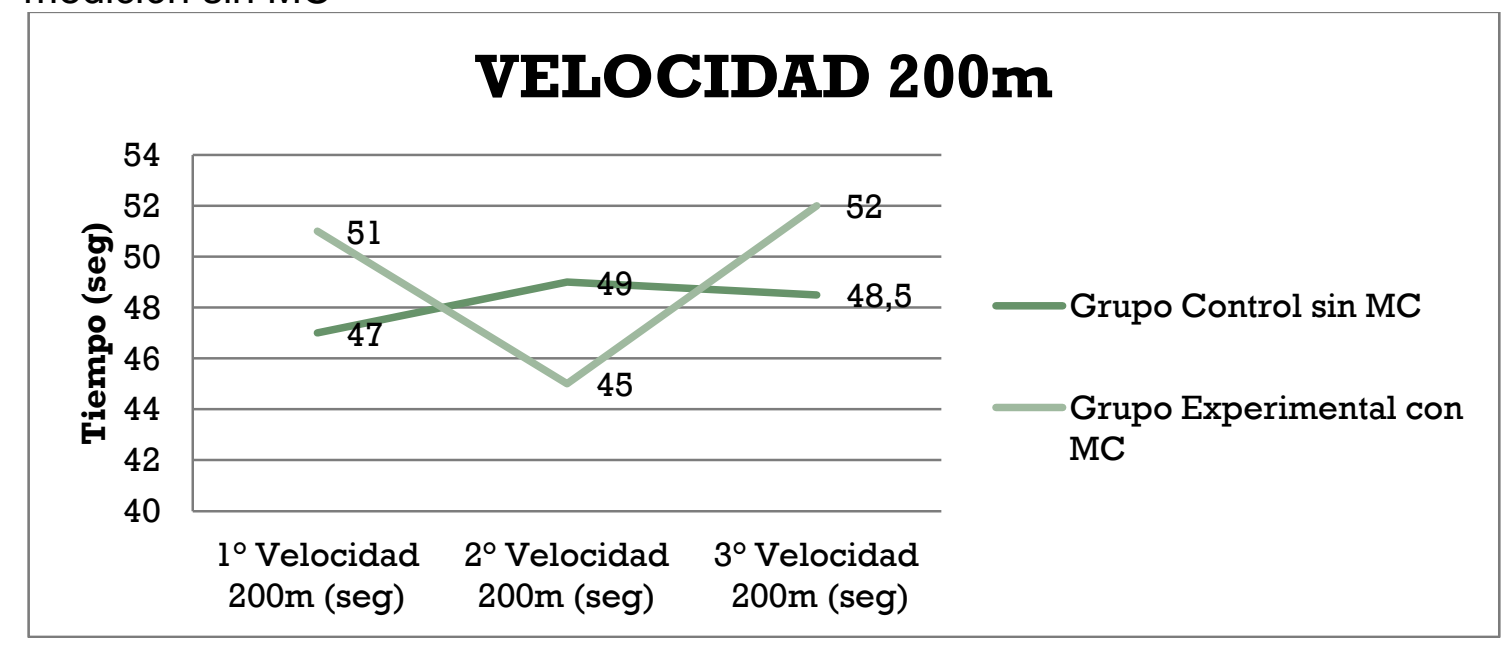

Rev. Ib. CL. Act.Fis. Dep. 


\section{Prueba Press en Banca}

La prueba tiene como objetivo valorar la capacidad de fuerza máxima del miembro superior (pectorales). Su ejecución consiste en disponer al deportista en decúbito dorsal sobre una banca de press horizontal y a la señal del controlador, el deportista deberá despegar la barra desde los apoyos y situarla frente a la línea imaginaria entre los hombros, desde allí descender la barra hasta llegar a tocar el pecho, y elevarla hasta llegar a la posición inicial. Se registrarán los kilogramos máximos que el deportista es capaz de elevar mediante extensión completa de sus brazos en una repetición.

La evaluación se efectuó en el lugar de entrenamiento (Gimnasio Fiscal, Talca), donde cada resultado se fue anotando en la hoja de registro de cada deportista.

Figura 6. Comparación de carga máxima en Press Banca en kg, muestra las diferencias entre el grupo control sin MC y grupo experimental donde indica la $1^{\circ}$ medición sin MC, la $2^{\circ}$ medición con MC y la $3^{\circ}$ medición sin MC.

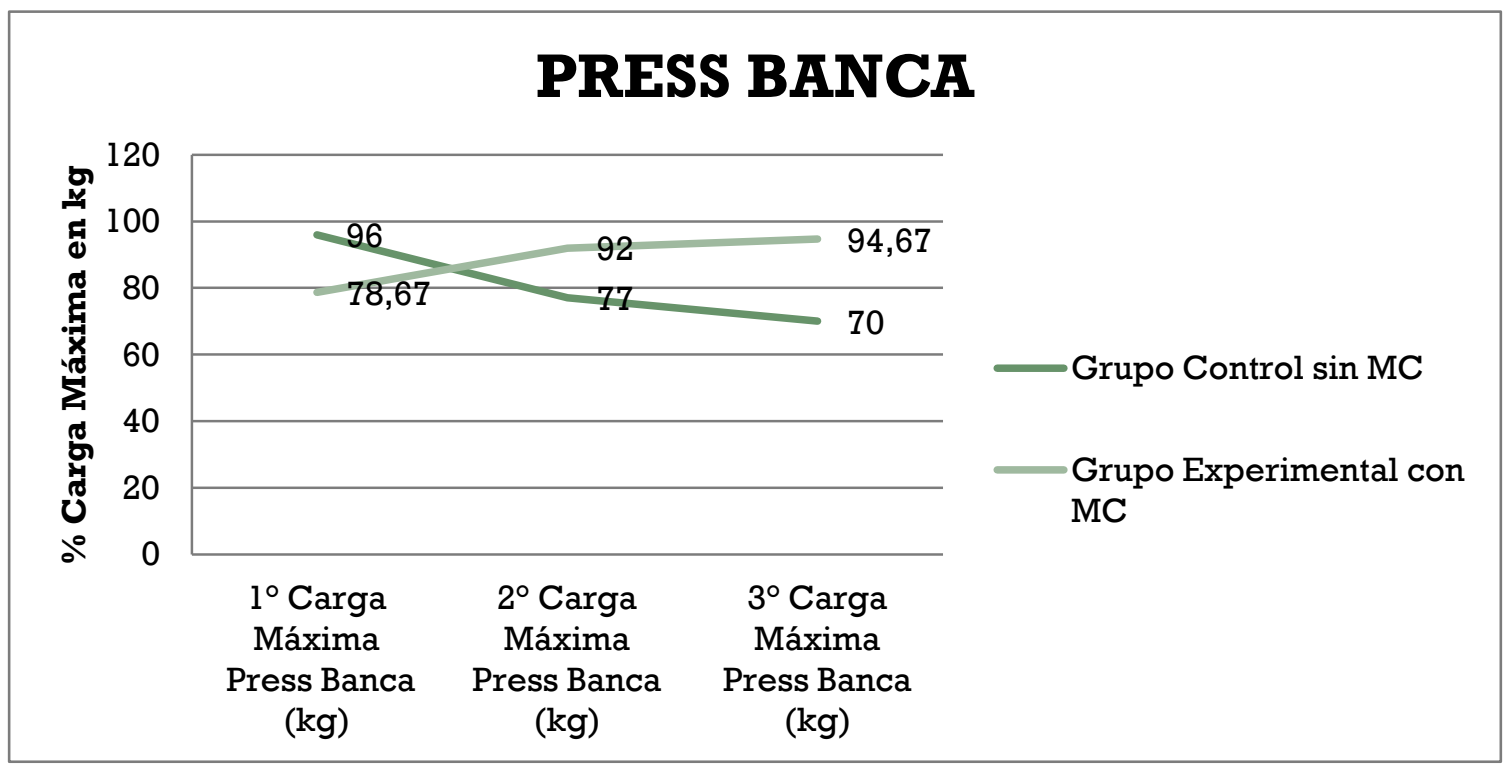

\section{Sentadillas}

La sentadilla tiene como objetivo potenciar la musculatura de muslos, cadera y glúteos y fortalecer ligamentos, huesos y tendones de piernas y cadera.

\section{Prueba Press Militar (Hombros)}

La prueba Press Militar tiene como objetivo fortalecer y potenciar la musculatura de hombro (trapecios, Tríceps, Deltoides).

Rev. Ib. CE. Act.Fis. Dep.

\section{Flexiones en barra fija}

La prueba Flexiones en barra tiene como objetivo fortalecer y potenciar la musculatura de tren superior (Dorsales, redondo mayor, romboides, subescapular, biceps), la prueba flexiones en barra consiste en suspenderse con los brazos desde una barra fija con el cuerpo suspendido sin contacto con el piso, desde esa posición el ejecutante debe hacer una flexión de brazos hasta superar el nivel de la barra con la barbilla, tomando la 
misma con las manos en pronación y elevando su cuerpo. Se cuentan la totalidad de repeticiones que efectúa el sujeto hasta la correcta ejecución y se termina el test cuando el deportista no es capaz de superar el nivel de la barra con la barbilla.

Figura 7. Comparación de repeticiones máximas en Barras, muestra las diferencias entre el grupo control sin MC y grupo experimental donde indica la $1^{\circ}$ medición sin $\mathrm{MC}$, la $2^{\circ}$ edición con MC y la $3^{\circ}$ medición sin MC.

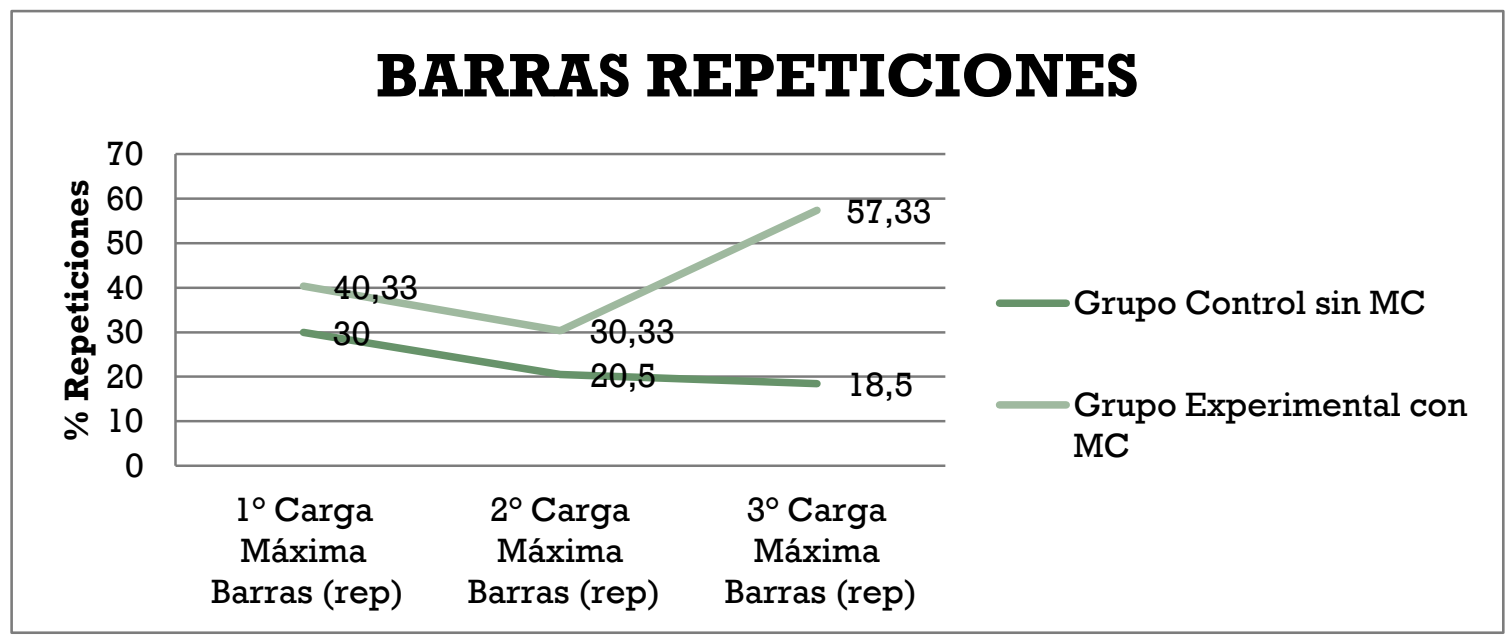

\section{Remo horizontal}

La prueba Remo horizontal tiene como objetivo fortalecer y potenciar la musculatura de tren superior (Dorsales, redondo mayor, trapecio, romboides, subescapular, bíceps), la prueba Remo horizontal consiste en ubicar al deportista en posición decúbito abdominal sobre una banca horizontal por debajo de la cual se sitúa una barra a la cual se le adicionan $\mathrm{kgs}$. de manera que el deportista ejecute la acción de tracción desde la máxima extensión de los brazos hasta tocar la base de la banca en una repetición con la máxima carga posible.

\section{DISCUSIÓN}

Esta investigación consideró a seis deportistas pertenecientes al Programa CER de canotaje del IND de la Región del Maule, Talca, entre los 14 - 18 años, divididos en dos grupos, grupo control integrado por 2 deportistas y grupo experimental integrado por 4 deportistas.

Considerando los acontecimientos ocurridos durante el desarrollo de la investigación y conforme con el grupo de profesionales que la integran, se tomo la decisión de dejar fuera a un deportista puesto que sufrió un cuadro respiratorio el cual to inhabilitó para desarrollar con normalidad el proceso, afectando su peso corporal (reducción de peso por deshidratación), lo cual dificultaba contar con información objetiva sobre la marcha de la preparación, provocando cambios relevantes en el análisis de los datos.

Por lo anterior, el estudio se realizó sobre 5 deportistas, de los cuales 3 de ellos (60\%) constituyeron el grupo experimental y 2 de ellos

$$
\text { Rev. Ib. CC. Act.Fis. Dep. }
$$


(40\%) el grupo control.

\section{Creatinkinasa (Ck)}

Se puede observar en Gráfico № 1 que nos arroja variaciones considerables de porcentaje, donde en la $1^{\circ}$ medición no se suministró el Monohidrato de Creatina arrojando una diferencia de 12,5 $\mathrm{U} / \mathrm{L}$ de $\mathrm{Ck}$ en sangre, siendo superior el grupo control al grupo experimental, en la $2^{\circ}$ medición el grupo experimental contaba con suplementación de MC evidenciándose una diferencia de porcentaje del 134,83 U/L de Ck. En la $3^{\circ}$ medición el grupo experimental mostró una diferencia de $181,33 \mathrm{U} / \mathrm{L}$ de $\mathrm{Ck}$ y en la $4^{\circ}$ medición donde ambos grupos estaban sin la ingesta de Monohidrato de Creatina, se presentó una diferencia del 33,5 U/L de Ck en sangre, nos da a conocer que los deportistas pertenecientes a ambos grupos iniciaron con un alto porcentaje de Ck en sangre, debido a que en esas instancias se realizaba el mismo trabajo físico, sicológico y no se estaba ingiriendo el Monohidrato de Creatina. Mientras que en el segundo examen, muestra una baja considerable en ambos grupos, en ese momento el grupo experimental se encontraba en una fase inicial de carga en conformidad a lo señalado en punto 3.4.1. En el tercer examen se puede observar un aumento de Ck en ambos grupos evidenciando mayor destrucción muscular, debido a que durante esa semana se efectuaron los controles de rendimiento.

Las curvas presentadas desde el inicio hasta el término del periodo muestran gran diferencia en números de una curva a otra, donde el inicio en la $1^{\circ}$ medición presenta un alto nivel del $\mathrm{Ck}$ en sangre $y$ terminando en la $4^{\circ}$ medición con una baja en ambos grupos tanto el de control como el experimental. En resumen el monohidrato de creatina fue un gran aporte para los deportistas, ya que pudieron mantener de forma regular los niveles de destrucción muscular sin correr el riesgo de un sobreentrenamiento, como en el caso contrario de los no experimentales que alcanzaron un nivel de destrucción muscular que podría convertirse en sobreentrenamiento si no es tratada a tiempo.

\section{Test de Potencia Anaeróbica y Resistencia}

Nuestros objetivos se enfocan principalmente en estos test, donde los deportistas deberían conseguir una mejora en los rendimientos deportivos y una disminución en los tiempos de sus competencias, de acuerdo a los Gráficos del № 2 al № 5

En el test de potencia anaeróbica de $200 \mathrm{~m}$ el grupo control inicia bajo el grupo experimental. El grupo control tiene un aumento de 2 segundos entre la $1^{\circ}$ y $2^{\circ}$ medición $y$ se mantiene entre la $2^{\circ}$ y $3^{\circ}$ medición, en tanto el grupo experimental en su $1^{\circ}$ medición sin MC en comparación con la $2^{\circ}$ medición con MC tiene una disminución de 6 segundos, manifestando una mejoría significativa del $11,7 \%$ y entre la $2^{\circ}$ y $3^{\circ}$ medición sin MC (mantención) vuelve a su tiempo de la $1^{\circ}$ medición. Este resultado demuestra que el suplemento con $\mathrm{MC}$ es relevante respecto de la mejora de la potencia anaeróbica 
láctica en conformidad a las condiciones del presente estudio, incorporando nuevo conocimiento respecto a lo señalado en la literatura especializada, que expone mejoras en pruebas de velocidad y fuerza. Es importante tomar nota del tiempo transcurrido entre la primera medición y la segunda medición de $200 \mathrm{~m}$ respecto de las fases de carga de MC, para efectos de proyectar su utilización a futuro durante la preparación directa a competiciones. El resultado de la tercera medición indica que no es posible asegurar una mantención de la mejora en potencia láctica durante la fase post carga de MC

En el test de 500m el grupo control, inicia sobre el grupo experimental en cuanto a tiempo (seg), teniendo un aumento entre la $1^{\circ}$ y $3^{\circ}$ medición de 2 segundos, en tanto el grupo experimental tiene una baja entre la $1^{\circ}$ medición sin $\mathrm{MC}$ y la $2^{\circ}$ con MC de 4,66 segundos, evidenciando una mejora significativa de $3,5 \%$ por efecto de la suplementación con MC, entre la $2^{\circ}$ y $3^{\circ}$ medición sin MC (mantención) existe una nueva baja de 2,34 segundos, resumiendo que entre la $1^{\circ}$ y $3^{\circ}$ medición es de 7 segundos, lo que da un $5,3 \%$ de mejoría del rendimiento producto del efecto residual del consumo de MC. En esta evaluación es posible evidenciar una mejoría notable desde la primera a la segunda medición (durante la fase de carga de $M C$ ), en una prueba eminentemente de resistencia anaeróbica láctica, que nuevamente nos permite aportar conocimiento nuevo sobre el particular, dado que la literatura no expone logros en esta fuente energética y que se explican probablemente por una mejora en la tolerancia al ácido láctico y por un aumento de las reservas intramusculares de glucógeno. Estas aseveraciones permiten establecer nuevas hipótesis de trabajo para futuras investigaciones.

En la resistencia de $1 \mathrm{~km}$ el grupo control inicia sobre el grupo experimental, pero no evidencia cambios entre la $1^{\circ}$ y $3^{\circ}$ medición. El grupo experimental tiene cambios significativos entre la $1^{\circ}$ y $3^{\circ}$ medición expresado en una disminución de 1,67 segundos que representan una mejoría de 3,9\%, a pesar del aumento de $1,01 \%$ entre la primera y segunda medición. Este resultado permite sugerir modificaciones positivas en la potencia aeróbica durante la fase sin aporte de MC siguientes a la etapa de mantención durante el segundo mesociclo de entrenamiento

En resistencia de $2 \mathrm{~km}$ el grupo experimental inicia bajo el grupo control. El grupo control entre la $1^{\circ} \mathrm{y}$ $2^{\circ}$ medición tiene un aumento en cuanto al tiempo, pero una disminución entre la $2^{\circ}$ y $3^{\circ}$ medición manteniendo un rendimiento similar entre la primera y tercera medición que no es significativo, el grupo experimental disminuye entre la $1^{\circ}$ medición sin MC y la $2^{\circ}$ medición con suplementación de $\mathrm{MC}$ de 14,33 segundos, que equivale a $2,2 \%$ de mejoría, evidenciando el efecto del consumo de $\mathrm{MC}$, mientras que entre la $2^{\circ}$ y $3^{\circ}$ medición sin MC aumentó en 20,33 segundos, disminuyendo su rendimiento. Se puede concluir que para esta prueba de capacidad aeróbica, la mejoría del rendimiento se produce durante la segunda fase

Rev. Ib. CL. Act.Fis. Dep. 
de carga de MC, perdiéndose su efecto durante la fase sin carga.

Tomando estas mediciones, la tendencia del grupo consumidor de MC en comparación al grupo control, es mejorar sus marcas y consecuentemente el rendimiento deportivo con la incorporación del suministro de MC, haciendo diferencias en los tiempos de mejora de cada fuente energética (tiempos en los test de rendimiento en diferentes distancias), respecto de cada una de las fases de carga, mantención y sin aporte de MC.

\section{Carga Máxima}

Otro de los aspectos que nos hace referencia nuestra hipótesis es mejorar el rendimiento que incluye el incremento de la fuerza y potencia. De acuerdo a los Gráficos № 6 y № 7, el grupo control sin $\mathrm{MC}$ en el primer test (Press Banca) inicia más alto que el grupo experimental, pero baja considerablemente desde la $1^{\circ}$ medición hasta la $3^{\circ}$, teniendo una disminución del $26 \%$, debido a las dificultades para mantener los procesos de adaptación a la carga del entrenamiento. El grupo experimental con $\mathrm{MC}$ inicia bajo el grupo control, en la $1^{\circ}$ medición sin suministro de $\mathrm{MC}$, en la $2^{\circ}$ medición que incluye la etapa de suplementación con MC aumentaron un $13,33 \%$ en $\mathrm{kg}$ y en la $3^{\circ}$ medición donde el grupo experimental se encuentra sin suplemento de MC se evidencia un aumento de $2,67 \%$ respecto del $2^{\circ}$ control y si observamos el inicio de la medición hasta el término de este, se ve un incremento de $16 \%$ en $\mathrm{kg}$.

Estos resultados evidentemente son significativos, en cuanto a que demuestran un importante progreso en la fuerza muscular, tal como lo señala la literatura, pero a un \% de progreso superior (13,33\%), la tercera evaluación demuestra una mejoría menor por encontrarse en una fase sin suplementación, lo que demuestra el efecto positivo de las fases de carga y mantención precedentes, demostrándose con ello el valor del MC en la mantención y mejoría de la fuerza a pesar de que el proceso de preparación del período básico tuvo una orientación preferente dirigida al desarrollo de la resistencia.

grupo control en cambio, disminuye sus niveles de fuerza producto de la carga de trabajo y del contenido del entrenamiento, confirmado por la baja de su \% de masa muscular.

En Barras (repeticiones) podemos observar que el grupo experimental inicia sobre el grupo control. El grupo control tiene una baja considerable entre la $1^{\circ}$ y $3^{\circ}$ medición de un $11,5 \%$ en número de repeticiones, mientras que el grupo experimental sufre una baja de $10 \%$ entre la $1^{\circ}$ medición sin MC y la $2^{\circ}$ medición con $\mathrm{MC}$, y un aumento de $27 \%$ en número de repeticiones entre la $2^{\circ}$ medición con $\mathrm{MC}$ y $3^{\circ}$ medición sin $\mathrm{MC}$ (mantención), obteniendo de esta manera un aumento entre la $1^{\circ} \mathrm{y}$ la $3^{\circ}$ medición de un $17 \%$ en número de repeticiones, lo cual es significativo. La baja mostrada en la segunda evaluación, se debe a la disminución de la cantidad de repeticiones que afectó a la deportista Camila Núñez, debido a que en ese momento se vio afectada por cambios hormonales derivados de su proceso de menstruación

Rev. Ib. CL. Act.Fis. Dep. 
Considerando que estos test nos demuestran la carga máxima en los deportistas y consecuentemente sus variaciones de fuerza muscular y resistencia de fuerza (en el caso de las flexiones en barra), podemos concluir que el suministro de MC permite incrementar el esfuerzo máximo, desplazar el tiempo de fatiga y cansancio de un deportista, logrando de esta manera aumentar su fuerza o disminuir sus tiempos de recuperación, que en este deporte trae mejoramiento en el desarrollo del entrenamiento, recuperación y consecuentemente en la mejora de las marcas para pruebas específicas.

\section{CONCLUSIONES}

De acuerdo a los objetivos planteados en la presente investigación cuantitativa de carácter descriptivo y a las características observadas en las variables analizadas de fuerza máxima, IMC, CK, composición corporal, hábitos nutricionales y test específicos en agua, según los deportistas evaluados: 5 hombres y 1 mujer pertenecientes al Programa C.E.R. de Canotaje del Instituto Nacional de Deportes de Chile, se ha llegado a las siguientes conclusiones.

La presencia de un cuadro respiratorio que afectó a uno de los sujetos de la investigación disminuyó su nivel de prestación, afectando su continuidad en el cumplimiento del proceso.

La medición de CK muestra datos similares en ambos grupos evidenciando mayor destrucción

Rev. lb. CL. Act.Fis. Dep. muscular durante la realización de los controles de rendimiento

La suplementación de MC mejora la fuerza y la resistencia de la fuerza en deportistas de canotaje.

La suplementación de MC y la metodología de entrenamiento aplicado, mejora los niveles de rendimiento en pruebas de potencia anaeróbica, capacidad anaeróbica, potencia aeróbica y capacidad aeróbica.

\section{Referencias bibliográficas}

1. Arasa, M. Manual de nutrición deportiva. Barcelona: Paidotribo; 2005

2. Bean, A. La guía completa de la nutrición del deportista. Barcelona: Paidotribo; 2005

3. Dietrich, M. Klaus, C. Klaus, L. Manual de Metodología del entrenamiento deportivo. Barcelona: Paidotribo; 2001

4. Garnés, R. Mas, O. Ayudas ergogénicas en el deporte. Lecturas: educación física y deportes. Revista Digital. 2005. 10, (86). Disponible en http://www.efdeportes.com/efd86/er gog.htm

5. Gispert, C. Manual de Educación Física y deporte. España: Editorial Oceano; 2005

6. González, J. Sánchez, O. Mataix, J. Nutrición en el deporte. Ayudas ergogénicas y dopaje. España: Díaz de Santos; 2006

7. IND. Proyección deportiva nacional, Centro de Entrenamiento Regional. Santiago; 2012

8. Latorre, A. Del Rincon, D. Arnal, J. Bases Metodológicas de la Investigación Educativa. Barcelona. Hurtado Ediciones; 1996.

9. López, J. Fernández A. Fisiología del ejercicio. Buenos aires: Editorial Médica Panamericana; 2006 
10. Richardson, V. Teoría general del entrenamiento deportivo olímpico. Barcelona: Paidotribo; 2001

11. Roberts, A. O' Brien M. Nutriceúticos: suplementos nutricionales, vitaminas, minerales. Barcelona. Robinbook; 2003

12. Santos, M. López, P. González, J. Moreno, A. Alonso, J. Cabañas, M. Pons, V. Porta, J. Arús, C. Efecto de la suplementación oral con monohidrato de creatina en el metabolismo energético muscular y en la composición corporal de sujetos que practican actividad física. Revista Chilena de Nutrición. 2003, 30 (1)

13. Vasconcelos, A. Planificación y Organización del entrenamiento deportivo. Barcelona: Paidotribo; 2005

14. Wilmore, J. Costill, D. Fisiología del esfuerzo y del ejercicio. Barcelona:

Paidotribo; 2007

Rev. Ib. Cᄃ. Act.Fis. Dep. 